\title{
O sexo e o gênero da docência*
}

\author{
Cláudia Pereira Vianna**
}

\begin{abstract}
Resumo
Nos debates educacionais, é consenso a constatação da enorme presença feminina no magistério. Bem menos freqüente, contudo, é a reflexão sobre os aspectos contraditórios geradores de tal processo. Pois essa é exatamente a proposta deste artigo: examinar a presença do sexo feminino no magistério, tomando por base as contribuições do conceito de gênero e sua construção histórica, social e cultural. As diferenças entre os sexos indicam diferentes significados masculinos $e$ femininos das identidades docentes e das relações escolares, assim como apontam para os desafios impostos pela articulação entre o sexo e o gênero da docência.
\end{abstract}

Palavras-chave: Sexo, Gênero, Magistério, Identidade Docente.

\footnotetext{
* Uma versão ainda inicial dessas reflexões foi apresentada no Primer Congreso Internacional sobre los procesos de Feminización del Magisterio, México, fevereiro de 2001. Essa nova versão contou com os preciosos comentários e contribuições de Gustavo E. Fischman e Maria Lúcia Spedo Hilsdorf. Recebido para publicação em setembro de 2001.

*** Professora doutora do Departamento de Administração Escolar e Economia da Educação da Faculdade de Educação da USP (FEUSP).
} 
O sexo e o gênero da docência

Sex and Gender in Theaching

\begin{abstract}
In the educacional debate there is a consensus about the predominance of women in the teaching profession. However, reflections concerning the contradictory aspects that generate such a phenomenon are less frequent. The objective of this article is to discuss such aspects, that is, to examine the presence of women in the teaching profession, based on the contributions of gender and its historical, social and cultural construction. The differences between the sexes suggest that there are masculine and feminine meanings associated with teacher's identity and with school relationships; they also point to the articulation between sex and gender in teaching.
\end{abstract}

Key Words: Sex, Gender, Theaching, Teacher's Identity. 
Ao longo do século XX, a docência foi assumindo um caráter eminentemente feminino, hoje, em especial na Educação Básica (composta da Educação Infantil, do Ensino Fundamental e do Ensino Médio), é grande a presença de mulheres no exercício do magistério.

De acordo com o primeiro Censo do Professor ${ }^{1}, 14,1 \%$ da categoria é constituída de homens e $85,7 \%$ de mulheres. Levantamento realizado pela Confederação Nacional dos Trabalhadores em Educação $(\mathrm{CNTE})^{2}$ com 52 mil professores ${ }^{3}$ brasileiros mostra que $97,4 \%$ dos docentes de $1^{\mathrm{a}}$ a $4^{\mathrm{a}}$ série do Ensino Fundamental são mulheres. Elas ocupam $80,6 \%$ das $5^{\text {as }}$ até as $8^{\text {as }}$ séries desse ensino e $60,8 \%$ do Ensino Médio. ${ }^{4}$ A pesquisa da CNTE aponta ainda que entre diretores, coordenadores $e$ supervisores ligados à Educação Básica $90,1 \%$ são mulheres.

A configuração desse processo, claro, tem sua história. A presença feminina no magistério pode ser observada ao longo de todo o século XIX nas chamadas escolas domésticas ou de improviso - algumas sem vínculos com o Estado e outras com

1 O Ministério da Educação (MEC), por meio de seu Instituto Nacional de Estudos e Pesquisas Educacionais (Inep), realizou em 1997, pela primeira vez em âmbito nacional, o Censo do Professor. O levantamento abrangeu 1.617.611 professores das redes pública e particular de ensino básico - mais de $90 \%$ da categoria, conforme dados do Inep - e teve como objetivo contribuir para um diagnóstico que orientasse as políticas educacionais. O Censo foi divulgado somente em 1999.

2 CoDo, Wanderley. (org.) Educação: carinho e trabalho. Brasília/Petrópolis, Universidade Nacional de Brasília/Confederação Nacional dos Trabalhadores em Educação/Vozes, 1998.

${ }^{3}$ Mesmo sabendo que a maioria do professorado está representada por mulheres, para facilitar a leitura e evitar a repetição constante do termo "professores/as", utilizo-me do masculino genérico para fazer referência ao grupo de docentes entrevistados. Porém, sempre que se faz necessária a distinção de sexo, procedo à diferenciação gramatical.

4 Trata-se da única fonte que mostra a presença feminina nos diferentes níveis $e$ modalidades do ensino brasileiro. A divulgação do Censo do Professor - 1997, embora indique a porcentagem total na Educação Básica, não divulga sua desagregação por sexo. 
O sexo e o gênero da docência

docentes já aprovados como funcionários públicos -, nas escolas seriadas instituídas após a República e com a progressiva extensão das escolas públicas. ${ }^{5}$

No ensino desenvolvido sob a responsabilidade do Estado, no Brasil, a docência feminina nasce no final do século XIX relacionada, especialmente, com a expansão do ensino público primário. ${ }^{6}$ Nos últimos anos do Império, sobretudo a partir de 1860 , mulheres assumem a função de professoras, fazendo parte do quadro de funcionárias públicas em várias províncias. Em grandes cidades como São Paulo e Rio de Janeiro a presença feminina no magistério público primário ganhou destaque. No estado de Minas Gerais, elas representam 50\% do corpo docente já no final do século XIX. No Estado de São Paulo, o acesso efetivo das mulheres às Escolas Normais para a formação de professores e professoras deu-se entre 1875 e 1880 com a criação

${ }^{5}$ Hilsdorf, Maria Lúcia Spedo. Tempos de escola: fontes para a presença feminina na educação, São Paulo - século XIX. São Paulo, Plêiade, 1999; FARIA FILHO, Luciano e VIDAL, Diana Gonçalves. Os tempos e os espaços escolares no processo de institucionalização da escola primária no Brasil. Revista Brasileira de Educação, São Paulo, ANPED/Autores Associados, $\mathrm{n}^{\circ}$ especial, mai/jun/ago, 2000, pp.19-34.

${ }^{6}$ A nomenclatura ensino primário tem diferentes conotações, conforme as modificações na legislação brasileira sobre a organização e o funcionamento do ensino. Do final do século XIX até meados do século XX, o curso primário dizia respeito à escolaridade elementar (com duração de 4 anos), seguido pela escola secundária, a qual, após a Reforma de Capanema, em 1942, passa a ser formada por dois ciclos: o ginásio (com duração de 4 anos) e o colégio, clássico ou científico (com duração de 3 anos). Em 1971, com a Lei 5692/71, o ensino brasileiro estruturou-se em três níveis: o Ensino de $1^{\circ}$ grau (com 8 anos de duração); o Ensino de $2^{\circ}$ grau, compulsoriamente profissionalizante (com 3 anos de duração para os que não pretendessem obter o diploma de técnico e com duração de 4 anos para os que desejassem obtê-lo); e o Ensino de $3^{\circ}$ grau de nível universitário. Em 1996, a Nova Lei de Diretrizes e Bases da Educação no 9394/96 institui apenas dois níveis de ensino: a Educação Básica compreendendo a Educação Infantil (creches e pré-escolas); o Ensino Fundamental (com duração de 8 anos); e o Ensino Médio, correspondente ao antigo $2^{\circ}$ grau sem caráter estritamente profissionalizante (com duração de 3 anos) - e a Educação Superior, de nível universitário. 
de uma seção feminina. ${ }^{7}$ No entanto, a presença cotidiana de mulheres não normalistas no magistério primário paulista, aprovadas em exames realizados pelas Câmaras Municipais, foi registrada no decorrer de todo o século XIX. ${ }^{8}$

No século $\mathrm{XX}$, o caráter feminino do magistério primário se intensificou a tal ponto que, no final da década de 20 e início dos anos 30, a maioria já era essencialmente feminina. O Censo Demográfico de 1920 indicava que $72,5 \%$ do professorado do ensino público primário brasileiro compunha-se de mulheres e, no total de docentes, sem distinção de graus de ensino, elas somavam $65 \% .{ }^{9}$ A presença feminina no magistério estendeu-se aos demais níveis de ensino após a progressiva expansão da oferta de vagas nos cursos de ensino primário em cidades de grande porte, como São Paulo, no final da década de 30 e meados de $1940 .^{10}$

Assim, desde o século XIX, pouco a pouco os homens vão abandonando as salas de aula nos cursos primários, $e$ as escolas normais vão formando mais e mais mulheres. Essa característica mantém-se por todo o século XX, estimulada, sobretudo, pelas intensas transformações econômicas, demográficas, sociais, culturais e políticas por que passa o país e que acabam por determinar uma grande participação feminina no mercado de trabalho em geral. Tendência, aliás, observada também em muitos outros países ${ }^{11}$, inclusive da América Latina, entre eles Uruguai, Venezuela, México e Brasil. ${ }^{12}$

7 Demartini, Zeila de Brito Fabri e AntunES, Fátima Ferreira. Magistério primário: profissão feminina, carreira masculina. Cadernos de Pesquisa. São Paulo, Fundação Carlos Chagas/Cortez, n 86 , agosto de 1993, pp.5-14.

8 Hilsdorf, M. L. S. Tempos de escola... Op. cit.

9 Demartini, Z. B. F. e Antunes, F. F. Magistério primário... Op. cit., p.7.

${ }^{10}$ Beisiegel, Celso de Rui. Ação política e expansão da rede escolar. São Paulo, CRPE, 1964.

${ }^{11}$ LoBo, Elisabeth Souza. A classe operária tem dois sexos: trabalho, dominação e resistência. São Paulo, Brasiliense/SMC, 1991; CAMPOS, Maria Christina Siqueira de Souza. Mulheres alçando vôo: familia e mercado de trabalho (19001950). São Paulo, CERU/Humanitas, 1997; HiRATA, Helena; LE DoARÉ, Hélene. 
O sexo e o gênero da docência

Nesse período, nota-se não só a propensão de as mulheres dirigirem-se ao ensino primário, tendo-o como mercado de trabalho, mas também a ampliação da presença feminina em outros níveis e modalidades de ensino. No final do século passado, o caráter fundamentalmente feminino da Educação Básica já estava mais que configurado.

Esse caráter remete a um fenômeno de amplitude internacional ${ }^{13}$, ainda que não universal; e no Brasil, já há algum tempo, muitos trabalhos vêm destacando a predominância feminina na composição sexual da categoria docente. ${ }^{14}$

Os paradoxos da globalização. In: FARIA, Nalu e NoBRE, Miriam. (orgs.) Cadernos Sempreviva - O trabalho das mulheres. São Paulo, SOF, 1999, pp.9-37; SCOTT, Joan Wallach. As trabalhadoras. In: DuBY, George e PERROT, Michèle. História das mulheres no ocidente. Porto/São Paulo, Afrontamentos/Ebradil, s.d.; Posthuma, Anne C. Mercado de trabalho e exclusão social da força de trabalho feminina. In: ABRAmo, Laís e ABrEU, Alice R. de Paiva.(orgs.) Gênero e Trabalho na sociologia latino-americana. São Paulo/Rio de Janeiro, ALAST, 1998, pp.21-82.

12 Abramo, L. e ABreu, A R. P. (orgs.) Gênero e Trabalho na sociologia latinoamericana. Op.cit; BRUSCHINI, Cristina. Gênero e trabalho no Brasil: novas conquistas ou persistência da discriminação (Brasil, 1985/95). In: RocHA, Maria Isabel Baltar da. (org.) Trabalho e gênero: mudanças, permanências e desafios. São Paulo, Editora 34, 2000.

${ }^{13}$ APPLE, Michael W. Trabalho docente e textos: economia política das relaçóes de classe e de gênero em educação. Porto Alegre, Artes Médicas, 1995; AraÚJO, Helena Costa. As mulheres professoras e o ensino estatal. Educação \& Realidade, vol. 16, n 2, 1990; NóvoA, António. Os professores: Quem são? Donde vêm? Para onde vão? Lisboa, ISEF, 1989; e Para o estudo sócio-histórico da gênese e desenvolvimento da profissão docente. Teoria \& Educação, Porto Alegre, Pannonica/UFRGS, n 4, 1991, pp.109-139; WiLliAmS, Christine 1. Still a man's world: men who do "women's work. Bekerley, University of California Press, 1995; ZAÏDAN, Claude. La notion de féminisacion: de la description statistique à l'analyse des comportaments. In: AUBERT, Nicole; ENRIQUEZ, Eugène; GAULEJAC, Vincent de. Le Sexe du povoir: femmes, hommes et pouvoirs dans les organisations. Paris, Desclée de Brower, 1986, pp.281-290.

${ }^{14}$ BRUSCHINI, Cristina e AMADO, Tina. Estudos sobre mulher e educação: algumas questões sobre o magistério. Cadernos de Pesquisa, São Paulo, Cortez/Fundação Carlos Chagas, $\mathrm{n}^{\circ}$ 64, fevereiro de 1988, pp.4-13; CARVALHO, Marilia Pinto de. No coração da sala de aula: gênero e trabalho docente nas séries iniciais. São 


\section{Cláudia Pereira Vianna}

No entanto, a incorporação do conceito de gênero na análise da feminização do magistério brasileiro é um fenômeno bem mais recente.

Paulo, Xamã, 1999; CARVAlHO, Marília e VIANNA, Cláudia. Educadoras e mães de alunos: um (des)encontro. In: BRUSCHINI, Cristina e SORJ, Bila. Novos olhares: mulheres e relações de gênero no Brasil. São Paulo, Marco Zero/Fundação Carlos Chagas, 1994, pp.133-58; CATANI, Denice Barbara et alii. (orgs.) Docência, memória e gênero: estudos sobre formação. São Paulo, Escrituras, 1997; CATANI, Denice Barbara. Os homens e o magistério: as vozes masculinas nas narrativas de formação. In: BuENO, Belmira. O. et alii. (orgs.) $A$ vida $e$ o ofício dos professores: formação contínua, autobiografia e pesquisa em colaboração. São Paulo, Escrituras, 1998; CosTA, Marisa. Trabalho docente e profissionalismo. Porto Alegre, Sulina, 1995; GouvEIA, Aparecida Joly. Professoras de amanhã: um estudo de escolha ocupacional. Rio de Janeiro, CEBRAP/INEP/MEC, 1965; LEWIN, Helena. Educação e força de trabalho feminina no Brasil. Cadernos de Pesquisa, São Paulo, Fundação Carlos Chagas, $\mathrm{n}^{\circ}$ 32, fevereiro de 1980, pp.45-59; LouRO, Guacira Lopes. Magistério de $1^{\circ}$ grau: um trabalho de mulher. Educação \& Realidade, Porto Alegre, vol. 14, nº 2 , jul./dez. 1989, pp.31-9; Mulheres na sala de aula. In: PRIORE, Mary del. (org.) História das mulheres no Brasil. São Paulo, Contexto/Ed. UNESP, 1997, pp.443481; NovaEs, Eliana. Professora primária: mestra ou tia? São Paulo, Cortez, 1984; Mello, Guiomar Namo de. Magistério de $1^{\circ}$ grau: da competência técnica ao compromisso político. São Paulo, Cortez, 1987; PEREIRA, Luiz. O magistério primário na sociedade de classe. São Paulo, FFCL/USP, Boletim de Sociologia, no 277, 1963; ROSEMBERG, Fúlvia e AMADO, Tina. Mulheres na Escola... Op. cit.; RAGO, Margareth. Trabalho feminino e sexualidade. In: PRIORE, M. del. (org.) História das mulheres no Brasil. Op. cit., pp.578-606; VIANNA, Cláudia Pereira Sexo e gênero: masculino e feminino na qualidade da educação escolar. In: AQUINO, Julio Groppa. Sexualidade na escola: alternativas teóricas e práticas. São Paulo, Summus, 1997, pp.119-130; Os nós do nós: crise e perspectivas da ação coletiva docente em São Paulo. São Paulo, Xamã, 1999; Organização docente paulista: crise, identidade coletiva e relações de gênero. Revista Brasileira de Educação, São Paulo, no 13, jan./fev./mar/abr. 2000, pp.54-72; VIDAL, Diana Gonçalves. Sexualidade e docência feminina no ensino primário do Rio de Janeiro (1930-1940). In: Bruschini, C. e HollandA, H. B. Horizontes plurais: novos estudos de gênero no Brasil. São Paulo, Fundação Carlos Chagas/Ed. 34, pp.281-314, entre outros. 
O sexo e o gênero da docência

\section{Gênero e feminização do magistério}

Até 1980, o tema das relações de gênero foi pouco explorado pelos estudos sobre educação no Brasil. ${ }^{15}$ Ainda hoje, nessa área, é escassa a reflexão sobre a relação entre homens e mulheres, assim como sobre os significados de masculinidade $e$ feminilidade com base nas relações de gênero. A passagem do feminino ao gênero, examinada já no início dos anos 90 por Castro e Lavinas ${ }^{16}$ na análise das abordagens sobre mulher $e$ trabalho, ainda está ausente da maioria das pesquisas sobre educação. Elas insistem em ver a escola como uma esfera perpassada quase exclusivamente por diferenças de classe, desconsiderando dimensões como gênero, geração e etnia/raça. ${ }^{17}$

Embora o exame do magistério com base na ótica das relações de gênero seja recente e escasso, ele apresenta reflexões interessantes sobre diversos aspectos: trabalho $e$ identidade docente, formação, currículo, construção do magistério, organização docente, entre outros temas.

Que contribuição o conceito de gênero pode oferecer, de modo que se veja a docência para além da mera presença do sexo feminino? São muitos os usos e os abusos do gênero, para

\footnotetext{
${ }^{15}$ BRUSChINI, C. e AMADO, T. Estudos sobre mulher e educação... Op. cit.; Rosemberg, Fúlvia e Amado, Tina. Mulheres na Escola. Cadernos de Pesquisa, São Paulo, Cortez/Fundação Carlos Chagas, nº 80, fevereiro de 1992, pp.62-74; SPONCHIADO, Justina Inês. Docência e relações de gênero: um estudo de dissertações e teses defendidas em instituições brasileiras no período de 1981 a 1995. Dissertação de Mestrado, PUC-SP, 1997.

${ }^{16}$ CASTRO, Mary G. e LAVINAS, Lena. Do feminino ao gênero: a construção de um objeto. In: COSTA, Albertina de Oliveira e BRUSCHINI, Cristina. (orgs.) Uma questão de gênero. São Paulo, Rosa dos Tempos/Fundação Carlos Chagas, 1992, pp.216-251.

${ }^{17}$ RosemberG, Fúlvia. Caminhos cruzados: educação e gênero na produção acadêmica. Educação e Pesquisa, São Paulo, Faculdade de Educação da Universidade de São Paulo, 2001, pp.47-68.
} 
empregar a feliz expressão de Heilborn. ${ }^{18}$ Com maior ou menor ênfase em suas interpretações, todos esses usos do gênero têm em comum a afirmativa da construção social das distinções sexuais como forma de resgatar a produção cultural e histórica das diferenças sexuais e das relações entre homens e mulheres. A busca seria por superar o determinismo biológico, o qual, baseado apenas nas diferenças de sexo e reforçado por argumentações provenientes da medicina e das ciências biológicas, tenta justificar a caracterização de mulheres $e$ homens como seres qualitativamente distintos.

$\mathrm{Na}$ educação, o determinismo biológico ainda se faz presente nos trabalhos que mencionam a presença feminina sem explorar as relações de gênero. Em pesquisa recente comprovei tal tendência em boa parte das dissertações e teses sobre organização docente no Brasil. ${ }^{19}$

Entre as várias concepções sobre as relações de gênero, destaco aquela que também ressalta seu caráter eminentemente cultural, enfatizando sua utilidade na análise da constituição dos significados e das relações de poder socialmente constituídas. ${ }^{20} \mathrm{O}$ saber que se produz sobre as diferenças sexuais e corporais, bem como sobre o lugar das mulheres na divisão sexual do trabalho, caracteriza-se pela sua variabilidade e natureza política. ${ }^{21}$

\footnotetext{
${ }^{18}$ Heilborn, M. L. Usos e abusos da categoria gênero. In: HollandA, Heloísa Buarque de. (org.) Y nosotras latinoamericanas? Estudos sobre gênero e raça. São Paulo, Fundação Memorial da América Latina, Relatório-Eventos. 1992.

${ }^{19}$ Vianna, C. P. Os nós do nós... Op. cit.

${ }^{20}$ ScotT, Joan Wallach. Gênero: uma categoria útil de análise histórica. Educação \& Realidade, Porto Alegre, vol. 16, n 2, jul./dez. 1990, pp.5-22; e Igualdad versus diferencia: los usos de la teoria postestructuralista. Debate Feminista, Mexico-D.F., vol. 5, março de 1992, pp.85-104; NiCHOLSON, Linda. Interpreting gender. Sings: journal of women in culture and society, Chicago, vol. 20, n 1 1, 1994, pp.79-105; IZQUIERDO, María Jesús. Uso y abuso del concepto de género. In: VilanOVA, Mercedes. (comp.) Pensar las diferencias. Barcelona, Universitat de Barcelona, 1994, pp.31-53.

${ }^{21}$ ScotT, J. W. Gênero como categoria útil... Op. cit.
} 
O sexo e o gênero da docência

Gênero, aqui, é empregado com a preocupação social, histórica e cultural de superar as explicações biologizantes acerca das "relações sociais fundadas sobre as diferenças percebidas entre os sexos" e com ênfase em sua definição como um "um primeiro modo de dar significado às relações de poder". ${ }^{22}$

Nossa socialização interfere na forma como nós - homens e mulheres - nos relacionamos, interfere nas profissões que escolhemos e na maneira como atuamos. Não se trata de afirmar que sempre foi assim ou que é inerente à nossa "natureza". Tratase, sim, de afirmar que as expressões da masculinidade e da feminilidade são historicamente construídas e referem-se aos símbolos culturalmente disponíveis em uma dada organização social, às normas expressas em suas doutrinas $e$ instituições, à subjetividade e às relações de poder estabelecidas nesse contexto.

As inúmeras decorrências desses pressupostos elevam a utilização do conceito de gênero a uma categoria explicativa muito fértil para a análise dos aspectos da docência. Muito mais pródiga de razões que a pura e simples composição sexual poderia sugerir.

\section{Feminização, igualdades e desigualdades}

A primeira decorrência indica que o sexo da docência se articula com a reprodução de preconceitos que perpetuam práticas sexistas. O processo de feminização do magistério associase às péssimas condições de trabalho, ao rebaixamento salarial $e$ à estratificação sexual da carreira docente, assim como à reprodução de estereótipos por parte da escola. ${ }^{23}$

\footnotetext{
${ }^{22}$ ID., IB., p. 14.
}

${ }^{23}$ As diversas características do trabalho docente, associadas ao processo de feminização carecem de mais pesquisas que nos forneçam informações sobre a possibilidade ou não de relação entre condições de trabalho, prestígio, rebaixamento salarial e estratificação sexual da carreira docente. Quanto à relação entre trabalho e relações escolares com os estereótipos de gênero ver VIANNA, Cláudia Pereira e RiDENTI, Sandra G. U. Relações de gênero e escola: das diferenças ao preconceito. In: AQUINO, Julio Groppa. Diferenças $e$ 
A opção do Estado pela expansão do ensino primário em meados do século XX dá-se mediante o prejuízo das condições do trabalho docente: a oficialização do magistério leigo; a redução da duração do curso primário para dois anos; a facilitação dos cursos normais de formação docente; a implantação do regime de funcionamento da escola em três ou quatro turnos; a construção de unidades escolares precárias e sem as mínimas condições para a atividade docente. ${ }^{24}$

Dificuldades semelhantes assolam o magistério após a ampliação desenfreada dos ginásios no final da década de 60. A ampliação do ensino secundário foi feita à custa da contratação de professores e professoras, na sua maioria a título precário, sem concurso e remunerados com verbas extraordinárias. Estas sempre foram exíguas se comparadas com o enorme crescimento do número de ginásios e dependiam da aprovação de dotações extras, "sujeitas às contingências da política financeira do governo, o que fazia com que os vencimentos docentes sofressem atrasos constantes". ${ }^{25}$

Atualmente, o contínuo processo de arroxo salarial $e$ as precárias condições de trabalho - que caracterizam igualmente tantas outras ocupações femininas - são características ainda muito presentes na docência e retratam um quadro de desencanto muitas vezes encarado como irreversível pelos professores. ${ }^{26}$

preconceitos na escola: alternativas teóricas e práticas. São Paulo, Summus, 1998, pp.93-106.

${ }^{24}$ Demartini, Z. B. F. e Antunes, F. F. Magistério primário... Op. cit., p.7.

${ }^{25}$ SPOSITo, Marília Pontes. O povo vai à escola: a luta popular pela expansão do ensino público em São Paulo. Coleção Educação Popular, n 2, São Paulo, Loyola, 1984, pp.69-70. Isso não ocorreu sem luta e protestos coletivos, que fortaleceram a organização docente, cf. VIANNA, C. P. Os nós do nós... Op. cit.

${ }^{26}$ VIANNA, C. P. Entre o desencanto e a paixão: desafio para o magistério. In: BrusChinI, C. e HollandA, H. B. Horizontes plurais... Op. cit., pp.315-342. 
O sexo e o gênero da docência

Soma-se a elas a estratificação sexual, geradora de guetos sexuais na carreira docente. ${ }^{27}$ As mulheres são maioria na Educação Básica, porém exercem atividades bem definidas na carreira. A Educação Infantil arregimenta mais de $90 \%$ das educadoras, enquanto no Ensino Superior as mulheres ainda são uma minoria, em especial nas carreiras tidas como masculinas.

Mesmo com a feminização da docência, os homens ainda ocupam as funções de maior prestígio social e recebem os salários mais altos. Em 1997, uma professora, de $1^{\text {a }}$ a $4^{\text {a }}$ série do Ensino Fundamental - função que abrange maioria absoluta de mulheres - recebia, em média, um salário mensal líquido de cerca de $\mathrm{R} \$$ 425,60, enquanto o rendimento médio docente no Ensino Médio (com quase $40 \%$ de homens) era de $\mathrm{R} \$ 700,19$ mensais. ${ }^{28}$ Pesquisa da $\mathrm{CNTE}^{29}$ constata a grande diferença salarial entre os distintos níveis da Educação Básica. Enquanto 17,4\% das professoras da pré-escola à $4^{a}$ série recebiam menos de $\mathrm{R} \$ 299,00$, apenas $7,1 \%$ dos docentes do Ensino Médio (com maior número de homens) viam-se na mesma condição. Nesse sentido, a utilização do gênero como categoria explicativa de análise ganha enorme utilidade para a compreensão da divisão/segregação sexual do trabalho contida na feminização da docência.

\section{Vida pessoal e profissional: tensões de gênero}

A segunda decorrência dos pressupostos de gênero para a análise da docência enquanto profissão feminina relaciona-se com os significados masculinos e femininos que permeiam a história de professores e professoras e suas práticas escolares. Como as

${ }^{27}$ Rosemberg, F. e AmADO, T. Mulheres na escola... Op. cit.; Educação formal e mulher: um balanço parcial. In: COSTA, A. O. e BRUSCHINI, C. (orgs.) Uma questão de gênero. Op. cit.

${ }^{28}$ Brasil, MeC/INEP. Censo Educacional... Op. cit.; Salário dos professores: ganho maior é no topo da carreira, INEP-Notícias, 29/02/2000. (http//www.inep.gov.br/notícias/news)

${ }^{29}$ CODO, Wanderley. (org.) Educação... Op. cit., p.247. 
concepções sobre o que é socialmente definido como masculino e feminino aparecem nas vidas de professores e professoras?

Os significados femininos e masculinos definem as relações entre professores/as e alunos/as no espaço escolar e no sindicato da categoria docente. Eles se baseiam nas diferenças entre os sexos, mas indicam também uma construção social - com base nessas diferenças - que ajuda a explicar as relações de poder que definem a divisão sexual do trabalho $e$ a inserção das mulheres em profissões ligadas a funções consideradas femininas $e$ socialmente mais desvalorizadas. ${ }^{30}$

O esquema binário que situa o masculino e o feminino como categorias excludentes estende-se para definições do que é ser homem e do que é ser mulher, professor e professora em nossa sociedade. Essa dicotomia cristaliza concepções do que devem constituir atribuições masculinas $e$ femininas e dificulta a percepção de outras maneiras de estabelecer as relações sociais. $\mathrm{O}$ cuidado, por exemplo, é visto como uma característica essencialmente feminina - para alguns uma responsabilidade natural, para outros, fruto da socialização das mulheres. Muitas atividades profissionais associadas ao cuidado são consideradas femininas, como a enfermagem, o tomar conta de crianças pequenas, a educação infantil, etc. $\mathrm{O}$ ato de cuidar, fundamental na relação com a criança, deve ser entendido como uma atividade que envolve compromisso moral.

Criam-se, assim, vários estereótipos sobre homens $e$ mulheres: agressivos, militaristas, racionais, para eles; dóceis, relacionais, afetivas, para elas. Em decorrência, funções como alimentação, maternidade, preservação, educação e cuidado com os outros ficam mais identificadas com os corpos e as mentes femininas, ganhando, assim, um lugar inferior na sociedade, quando comparadas às funções tidas como masculinas. ${ }^{31}$

${ }^{30}$ ScOTT, Joan Wallach. Prefácio à Gender and Politics of History. Cadernos Pagu (3), Campinas, Núcleo de Estudos de Gênero - Pagu/UNICAMP, 1994, p.11-28.

${ }^{31}$ IZQUIERDO, M. J. Uso y abuso... Op. cit., pp.31-53. 
O sexo e o gênero da docência

Para compreender a constituição do eu e as relações sociais que marcam essas características, é preciso recorrer a esses modos de ser e pensar lineares, hierárquicos e binários, fortemente predominantes na cultura ocidental. Mas também é necessário ultrapassá-los e buscar a diversidade caracterizadora da identidade docente, considerando o cotidiano escolar de professores $e$ professoras não como determinismos locais fragmentados ${ }^{32}$, e sim como um importante aspecto da organização social formadora de professores e professoras como sujeitos contraditórios e capazes de superar essa visão bipolar hegemônica.

Em minha tese de doutoramento ${ }^{33}$, pude verificar que, tanto no plano individual quanto no profissional, os significados masculinos e femininos historicamente atribuídos ao professorado e à profissão docente são contraditórios e múltiplos.

Ao falarem de suas diferentes concepções sobre o exercício da profissão, professores e professoras remetem às próprias experiências, apontando tensões entre os significados masculinos e femininos tradicionais e tentativas de transformação desses valores.

Mais do que isso: não existe relação direta entre vida pessoal e atividade profissional. Os significados inovadores do que é ser homem e ser mulher na vida privada não redundam necessariamente em ressignificações do masculino e do feminino no campo da configuração da identidade docente. Uma postura fortemente tradicional na vida privada pode se somar a um papel inovador na esfera da prática docente no cotidiano escolar. Assim, a socialização na vida privada não marca diretamente todas as significações do masculino $e$ do feminino no campo da configuração da identidade docente.

${ }^{32}$ É o caso de Gilligan e sua defesa do feminismo da diferença como fruto da oposição de homens e mulheres tão-somente como grupos diferenciados e não como desigualdades decorrentes das tensões sociais. GILLIGAN, Carol. Uma voz diferente: psicologia da diferença entre homens e mulheres da infância à idade adulta. Rio de Janeiro, Rosa dos Tempos, s/d.

${ }^{33}$ ViAnNA, C. Os nós do nós...Op. cit. 
Para melhor exemplificar, apresento a seguir relatos de professoras e professores, colhidos em minha pesquisa de doutoramento. São docentes da rede de ensino estadual paulista ${ }^{34}$ que atuam da $1^{\mathrm{a}}$ à $4^{\mathrm{a}}$ série do Ensino Fundamental e da $5^{\mathrm{a}}$ série do Ensino Fundamental à $3^{a}$ série do Ensino Médio.

A primeira tendência que se verifica nos relatos é o peso dos significados tradicionais da masculinidade e da feminilidade. Barros, professor das $7^{\text {as }} e 8^{\text {as }}$ séries do Ensino Fundamental, é um exemplo dessa percepção. Como filho mais velho, assumiu a responsabilidade pelo sustento da mãe, da irmã e das sobrinhas após a separação de seus pais. O papel de homem provedor vem em primeiro plano no seu discurso, atrelado ao modelo tradicional masculino, que vê no homem o único responsável pelo sustento da família.

Trata-se da assunção do papel social de provedor atribuído ideologicamente aos homens e reiterado por esse professor no âmbito individual. Ao mesmo tempo, porém, anuncia a tensão resultante da necessidade de assumi-lo:

Eu já paguei todas as dívidas que tinha, vai ser possível pagar o IPTU este mês, da minha casa. Eu me tornei na minha casa o chefe da casa. Incrível. (...) E de um tempo para cá ele [seu pai] pergunta se está tudo bem em casa, ele quer ajudar financeiramente. Ele tem dinheiro, meu pai. Mas eu falo para ele que não precisa, eu minto para ele. (...) Não vou pedir nada para ele, para ele está tudo bem. (...) Eu tenho orgulho próprio. Eu tenho orgulho próprio, sou uma pessoa orgulhosa, entendeu? (...) Eu sou o filho mais velho, só. É uma coisa que carrego. Uma... é uma, como é a palavra, é... um compromisso, não é a palavra. Uma necessidade, eu não sei. (...) uma responsabilidade.

Colocando em segundo plano seus projetos pessoais $e$ profissionais, Barros mostra-se pressionado e desestimulado diante

${ }^{34}$ Os nomes dos professores são fictícios. 
O sexo e o gênero da docência

das pressões familiares e econômicas. Está cansado de ser o chefe de família e lamenta viver sempre com o carro quebrado e não ganhar o suficiente para comprar um modelo mais novo:

Eu fiquei três meses andando a pé, de ônibus e bicicleta.

Até que eu tive outro dia uma queda da bicicleta, os professores fizeram uma campanha aqui para que eu [consertasse o carro] e uma professora (...) conseguiu com o mecânico que eu pagasse a prestação (...) só que de repente andei duas semanas com o carro e quebrou de novo. (...) Vim para cá de ônibus, por isso que eu atrasei um pouco. Desanima.

Barros lembra também seu constrangimento diante da necessidade de aceitar doações de alimento e bens quando sua casa foi atingida pela enchente. Lastima não conseguir arcar com o custo do curso de informática da irmã. Chega a considerar a possibilidade de assumir aulas de história e geografia em escolas particulares, mas prefere deixá-la como um último recurso de sobrevivência, revelando que essa alternativa o desagrada.

Como se vê, Barros vive um grande conflito na condição de principal responsável pela família. Ainda assim, apesar de ser esse um peso que carrega, talvez um fardo do qual gostaria de se "livrar", absorveu o valor de que os homens são os responsáveis pelos familiares incapazes de se sustentar. Tal postura revela a tensão que Barros vivencia ante os valores relativos à responsabilidade masculina. Mas, mesmo em conflito, ele não questiona essa função tão diretamente relacionada com a concepção dominante de masculinidade. A idéia do homem "filho mais velho", "chefe da casa" e responsável pela família parece cristalizada nele.

Mesmo fazendo parte de uma sociedade na qual muitas mulheres são chefes de família e/ou assumem para si a responsabilidade e a manutenção da vida familiar - como algumas das professoras entrevistadas -, Barros ainda revela uma concepção tradicional de masculinidade e feminilidade, e assume 
o papel de provedor. Isso, provavelmente, porque todos nós continuamos a conviver com esse padrão de masculinidade na sociedade brasileira, apesar da inegável maior aceitação da presença feminina nas atividades de trabalho exercidas fora de casa.

As considerações de Margareth Arilha ${ }^{35}$ sobre a forte relação entre a palavra "responsabilidade" e os homens adultos, ainda presente em nossa sociedade, parecem elucidar a posição de Barros. Entretanto, em contraposição à idéia da responsabilidade masculina mediante a paternidade, ele se recusa a constituir sua própria família, embora assuma o cuidado da família paterna:

Sou o chefe de casa. Por isso que até não quero casar, ter filho, que já estou de saco cheio. Saco cheio de família. Mas eu quero bem minha mãe, quero bem minha irmã, quero que minha irmã se dê bem, quero que meu pai se dê bem. (...) A minha família vive em harmonia.

Desse modo, desempenha o papel de "chefe desta família", uma vez que o pai os abandonou, mas sempre em conflito. Sentese tenso diante de "tamanha responsabilidade", reclama do fardo, mas não toma nenhuma atitude para minimizar ou recusar esse papel atribuído aos homens pela sociedade.

Diante de toda essa carga emocional e social que Barros carrega ao assumir por completo a função de homem provedor, seria possível supor que, na escola, essa visão também se fizesse presente nas suas relações com professores e professoras, pais mães de alunos/as.

Todavia, não é isso que acontece na sua experiência docente. $\mathrm{O}$ peso dessas concepções tradicionais, porém, não o impede de questionar a idéia convencional de masculinidade e feminilidade, ligada à submissão ou, simplesmente, à não

${ }^{35}$ ARILHA, Margareth. Homem: entre a "zoeira" e a "responsabilidade". In: ARILHA, M.; RIDENTI, Sandra G. U.; MEDRADO, B. Homens e masculinidades: outras palavras. São Paulo, ECOS/Ed.34, 1988, pp.51-78. 
participação das mulheres, quando se refere ao papel feminino nas ações coletivas da categoria docente.

A segunda tendência entre muitos dos relatos sobre a vida pessoal diz respeito às tentativas de negar os padróes tradicionais de masculinidade e feminilidade.

Gérson, professor das últimas séries do Ensino Fundamental, vive uma situação familiar muito semelhante à de Barros. Entre os homens, ele é o mais velho dos irmãos. Mora com a mãe e a irmã, que sofrem de depressão. Preocupa-se com a condição das duas e assume a responsabilidade por elas e pelos sobrinhos, uma vez que seu pai e seu cunhado não vivem com eles:

Eu tenho essa característica de paizão. Eu sou muito ligado a minha família. (...) Minha família é a minha. (...) Meu pai separou, eu assumi. Tinha meus sobrinhos pequenos - eles me chamam até de pai.

Assim como Barros, Gérson se angustia diante das responsabilidades assumidas com a família: "Você já trabalha o dia todo, já segura aquela barra... Aí você chega em casa, você está com sua mãe doente". Mas, mesmo nessas condições, ele se diferencia de Barros, pois não assume responsabilidade total e cria certo distanciamento em relação à família:

Eu ficava muito ansioso e queria ligar toda hora que tivesse... (...) Não estava sendo legal para mim, porque eu ficava muito ansioso. (...) então eu falei: "Eu vou dar o telefone para minha irmã, se ela estiver mal, ela me liga". (...) comecei a me afastar de muitas coisas (...) Então, eu acho que consegui superar esse momento.

Gérson, como se vê, cuida da família, mas, além disso, cria condições para conseguir trabalhar com alguma tranqüilidade $e$ delega responsabilidades para a irmã e os sobrinhos. 
Lúcio, professor das $5^{\text {as }}$ séries do Ensino Fundamental, também questiona o padrão de masculinidade em sua prática individual, ao procurar construir outro modelo de paternidade. Quer cuidar de suas duas filhas, divide essa função com a companheira e busca exercer mais de perto a função de pai: "Poder acompanhar as crias de perto, né? Deixar elas crescerem com carinho, poder brincar mais".

Elisa, professora das $1^{\text {as }}$ séries do Ensino Fundamental, relata situações de tensão e ambivalência quanto aos padrões de feminilidade e tenta ser diferente ao traçar seus projetos pessoais como mulher. O que para Barros é motivo de conflito interior, para ela é elemento de definição. Decidiu não se casar para ter liberdade de construir a própria vida e está economizando parte do salário para morar sozinha em um apartamento, comprar móveis e eletrodomésticos.

Além disso, considera que não corresponde ao modelo "mulher casada", que, na sua concepção, soma ao trabalho fora de casa, necessariamente, as tarefas domésticas e familiares:

Eu não me vejo assim, tendo que tomar conta de filho, de marido, igual a minha irmã mais velha, que é casada. (...) limpando casa... eu não me vejo assim, nessa situação (...) A mulher ainda vai carregar isso, ainda por longos tempos. Até formar a cabeça desses homens ao contrário, eu acho que ela vai carregar esse peso por muito tempo ainda. E eu, como já sei que não sirvo para a coisa, então não está nos meus planos casar.

Elisa revela seu envolvimento com a profissão, na qual deseja permanecer, e a compreensão de que em nossa sociedade, como diz ela, "machista", o trabalho de casa interfere no trabalho fora dela, este sim, a seu ver, símbolo da busca de independência pelas mulheres. A professora recusa a concepção tradicional do papel feminino em relação à vida doméstica: boas cozinheiras, donas-de-casa perfeitas, dedicadas aos filhos e ao marido. Não existe meio-termo: "Ou você não faz, ou você faz bem feito". 
O sexo e o gênero da docência

Elisa reconhece que as mudanças ocorridas nas últimas décadas deslocaram a mulher de seu papel tradicional: maior presença feminina no mercado de trabalho e novos padrões nas relações entre homens e mulheres indicando certa divisão das tarefas domésticas. Ao enfatizar que a mulher pode se dedicar exclusivamente ao trabalho, não ter filhos nem marido $e$ investir em projetos pessoais, Elisa constata a existência de muitas formas de masculinidade e feminilidade, como aponta Connell. ${ }^{36}$ Mas percebe também a difícil compatibilidade entre trabalho e tarefas domésticas na vida das mulheres. Talvez por isso opte pela negação do casamento como uma das expressões do modelo convencional de feminilidade e tome providências para realizar seus planos sozinha.

No entanto, toda essa ruptura de Elisa com um modelo tradicional de ser mulher, mãe, dona-de-casa, não a impede de assumir uma postura individualista, não contestadora e maternal com seus alunos e nas relações escolares.

Dora, professora das $1^{\text {as }}$ séries do Ensino Fundamental, ao contrário de Elisa, é casada e interrompeu por alguns anos sua trajetória profissional para cuidar dos filhos. Só mais tarde, quando eles já tinham cerca de 4, 5 anos, voltou a dar aulas em uma escola próxima de sua casa, não aderindo completamente ao modelo "mulher/dona-de-casa", como diz, dirigido exclusivamente ao cuidado dos filhos.

Uma vez de volta ao trabalho, optou pelo período integral manhã e tarde. Para poder conciliar a atividade docente com as atividades domésticas, equipou a casa com aparelhos que simplificam as tarefas, levanta cedo e já deixa a comida pronta no microondas.

Essa trajetória foi percorrida em meio a muitos conflitos. No âmbito das relações de gênero, a tensão entre permanência $e$ mudança marca sua vida pessoal e profissional. De um lado,

${ }^{36}$ ConNel, Robert W. Políticas da masculinidade. Educação \& Realidade, Porto Alegre, vol. 2, n² 20, 1995, pp.185-206. 
permanece voltada para o trabalho doméstico e para o cuidado dos filhos. De outro, procura não abrir mão da profissão que escolheu, dedicando-se a ela integralmente e buscando na docência a realização pessoal e profissional. Essa opção é facilitada pelo fato de o marido receber o suficiente para sustentar a família, arcar com os gastos domésticos e as despesas com os filhos: "Eu não dependo do salário. Eu realmente trabalho não porque eu precise do dinheiro; é uma realização pessoal, profissional mesmo".

Além de sua preocupação em realizar-se profissionalmente, destaca a necessidade de manter uma relativa independência em relação ao marido:

Eu sou uma pessoa independente, tá? Eu não consigo depender. (...) Eu sempre fui independente dos meus pais também. Desde os 13 anos que eu fazia magistério, tá? (...) Não gosto de satisfação: para que é isto? Para que é aquilo? Se eu vejo um negócio eu compro para meus filhos, não fico esperando lá o consentimento. Não gosto, não gosto, não gosto.

Essa atitude não é tomada impunemente: Dora sofre pressões do marido para que abandone a profissão, considerada por ele pouco satisfatória e, mesmo assim, insiste em permanecer no magistério. Engaja-se em atividades coletivas na escola $e$ assume uma postura contestadora $e$ ativa, discutindo com pais $e$ mães de alunos/as e enfrentado a direção.

Ainda que de modo diferente de Dora, Rita também procura construir um modelo alternativo de feminilidade tanto em sua vida pessoal quanto na escola. Ela não se casou, vive sozinha $e$, por anos a fio, sofreu as conseqüências de procurar superar seus problemas financeiros, enfrentando dificuldades para conseguir manter-se independente.

Comenta seu empenho para obter outra fonte de renda com a qual pudesse arcar com as despesas da casa, viajar de vez em quando, pagar seus cursos de especialização e permanecer no 
O sexo e o gênero da docência

magistério público, até, por fim, ter sido aprovada para uma vaga em um instituto de pesquisa:

Eu tinha que achar uma solução para o problema, é um problema que está colocado, você não vive como professora, sobretudo eu que não sou casada, tenho que viver assim... tenho que sobreviver da minha própria... É complicada essa questão (...) Você não sobrevive. (...) Chegou uma hora que eu tive que resolver esse problema. (...) Eu cheguei à conclusão que eu ia procurar uma outra coisa para somar à minha atividade profissional (...) Então hoje, por exemplo, eu não sou das mais desesperadas lá dentro da escola nesse sentido, eu arrumei um outro trabalho, procurei durante muitos anos, até achar esse lá no Instituto. (...) eu trabalho poucas horas, faço um trabalho completamente diferente, ganho um dinheiro razoável, um dinheiro muito diferente do que eu ganho [na escola].

A principal razão das dificuldades financeiras de Rita está em sua forte relação com o magistério. Seu empenho em conseguir uma atividade paralela explica-se pela decisão de permanecer como professora do ensino público e achar uma solução que também garantisse sua independência econômica:

Se não mantivesse um outro trabalho eu não poderia morar aqui em São Paulo, eu teria que morar num lugar onde eu pudesse sobreviver com o meu trabalho de professora. (...) Porque lá [a escola] eu não vou largar, eu já me questionei a respeito, lá eu não vou largar. A minha vida inteira eu trabalhei nisso, é o que eu sei fazer, é o que eu gosto de fazer, eu não vou mudar minha vida inteira nem tenho razão para isso, nem tenho motivo para isso.

Assim, professores $e$ professoras mostram as tensões $e$ contradições que permeiam suas vidas pessoais e profissionais sob a ótica das relações de gênero. Ora referendam papéis tradicionais reservados aos homens $e$ às mulheres em nossa sociedade, ora 
procuram imprimir relações mais igualitárias em suas vidas $e$ negar, ainda que parcialmente, alguns valores tradicionais de masculinidade e feminilidade. Vivenciam a tensão que caracteriza a vida pessoal e profissional de cada um ao abraçarem de modo distinto os significados de homem/provedor e "paizão" $e$ da mulher que arca sozinha com seus projetos ou com a qual o homem pode dividir a responsabilidade pela família.

Nesse processo, eles se colocam em constante tensão com as alternativas convencionais reservadas a homens e mulheres. São homens sobrecarregados pela função de provedores, mulheres sobrecarregadas pelas atribuições maternas, mulheres que questionam a trajetória convencional feminina no casamento, homens que incorporam amiúde o cuidado dos filhos em suas relações familiares.

Mais ainda: essa tensão também aparece nos significados masculinos e femininos relacionados ao magistério. Esses significados da biografia pessoal organizam a identidade docente de modo contraditório e indireto ao indicar sinais de reprodução, mas também de ruptura com modelos tradicionais e apontar desafios e tensões vividas por professores e professoras. 